Supplement of Nat. Hazards Earth Syst. Sci., 14, 1835-1841, 2014

http://www.nat-hazards-earth-syst-sci.net/14/1835/2014/

doi:10.5194/nhess-14-1835-2014-supplement

(C) Author(s) 2014. CC Attribution 3.0 License.

(c) (i)

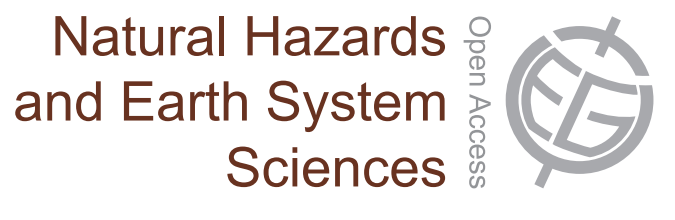

Supplement of

Brief Communication: Rapid mapping of landslide events: the 3 December 2013 Montescaglioso landslide, Italy

A. Manconi et al.

Correspondence to: A. Manconi (andrea.manconi@irpi.cnr.it) 


\section{Supplementary Material of the Manuscript}

2 S1 Stereoscopic aerial photographs used to prepare the landslide inventory map of the Montescaglioso

3 study area. The images are available at the website of the Istituto Geografico Militare Italiano (IGMI)

4 (http://www.igmi.org/voli/).

\begin{tabular}{|c|c|c|c|c|}
\hline YEAR & STRIP & PHOTOGRAPH & TYPE & SCALE \\
\hline 1947 & 6 & $45 \mathrm{c}, 46 \mathrm{c}, 47 \mathrm{c}, 48 \mathrm{c}, 49 \mathrm{c}, 45 \mathrm{~s}, 46 \mathrm{~s}, 47 \mathrm{~s}, 48 \mathrm{~s}, 49 \mathrm{~s}$ & black-and-white & $1: 24,000$ \\
\hline 1954 & 152 & $6950,6951,6952$ & black-and-white & $1: 34,000$ \\
\hline 1972 & $3 \mathrm{bis}$ & $5522,5523,5524$ & black-and-white & $1: 30,000$ \\
\hline 1989 & 36 & $44,45,46$ & black-and-white & $1: 27,000$ \\
\hline 1990 & 31 & $731,732,733$ & black-and-white & $1: 36,000$ \\
\hline 1996 & 38 & $90,91,92,93$ & black-and-white & $1: 34,000$ \\
\hline 2003 & 131 & $6107,6108,6109,6110$ & black-and-white & $1: 30,000$ \\
\hline 2003 & 126 & $6157,6158,6159$ & black-and-white & $1: 30,000$ \\
\hline
\end{tabular}

5

6 
7 S2. Landslide inventory map realized along the SW slope of the hill where is located the

8 Montescaglioso village. The map is carried out by the photointerpretation of different sets of 9 stereoscopic aerial photographs taken in the period 1947-2003. The map shows: (i) a very old landslide (light green in the map); (ii) slide, slide flows and flows (violet in the map) distributed inside and at the

11 boundary of the very old landslide; (iii) main landslide escarpments and (iv) alluvial fan deposit (light 12 blue in the map). Superimposed to the pre-existing landslides, in orange is represented the 3 December 2013, Montescaglioso landslide. The base map is the WMS 2006 color orto-photomap, downloaded

\section{4 from http://www.pcn.minambiente.it.}

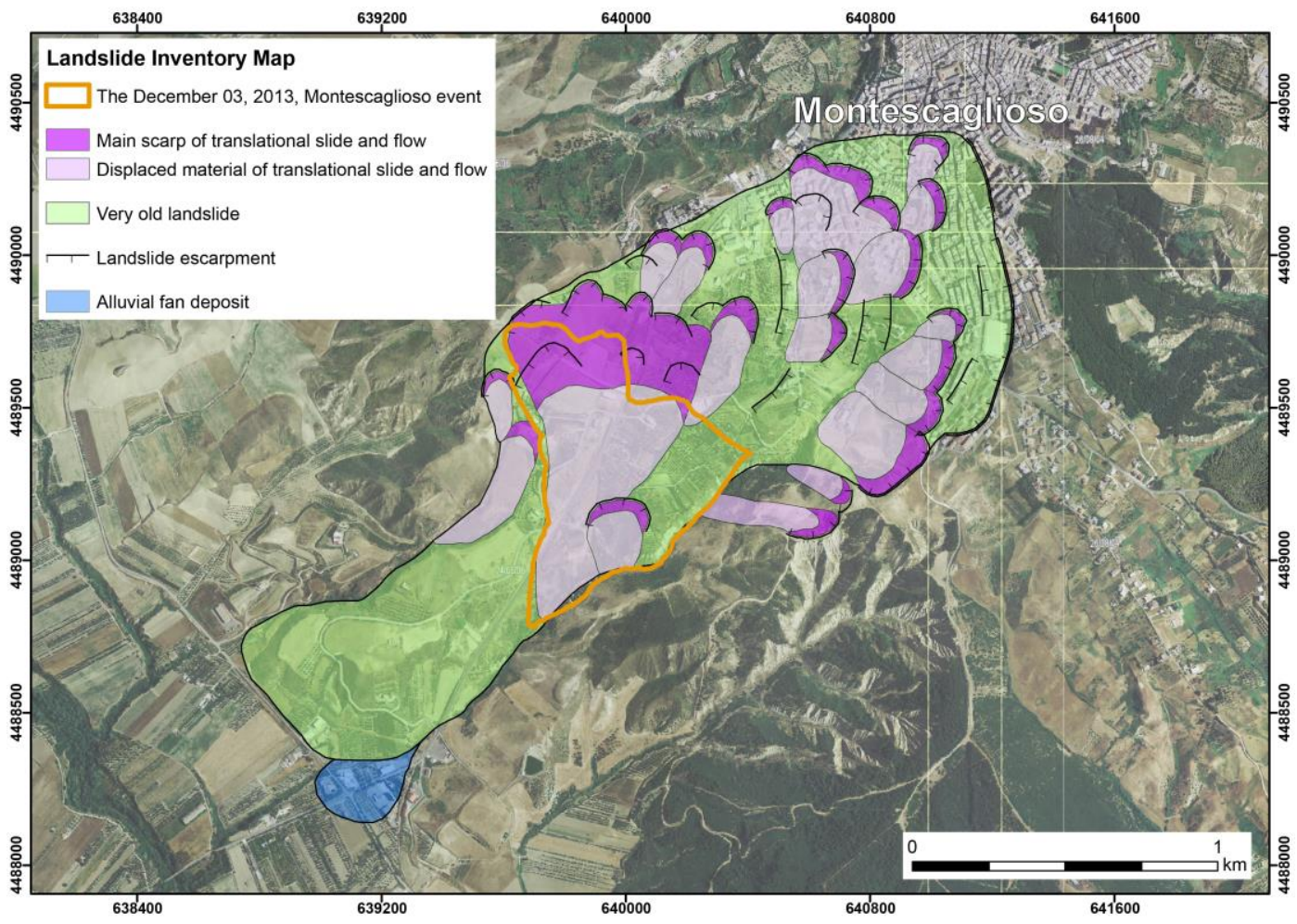


S3. High resolution map of the surface deformation produced by the new Montescaglioso landslide, as identified by field surveys. The moving mass determined the formation of pressure ridges and thrusts for some hundreds of meters, as well as the damming of Fosso Capoiazzo, with consequent formation of several lakes. In particular, the area of the original confluence between the two water lines (Canale Cinque Bocche and Fosso Capoiazzo, see also Fig. 1) was considerably modified, being strongly altered the hydrographic network due to the accumulation of the material pushed from upstream. A further lake was formed at this site, too. The morphological characters observed and mapped indicate that the phenomenon was a translational slide, with main direction of movement towards SW. In its middle-lower portion, because of the obstacle constituted by the body of an ancient paleo-landslide delimited by the two water lines mentioned above, the direction of the main movement changed toward SSW, strongly conditioned by the right flank of the landslide, approximately striking NS. The base map is the WMS 2006 color orto-photomap, downloaded from http://www.pcn.minambiente.it.

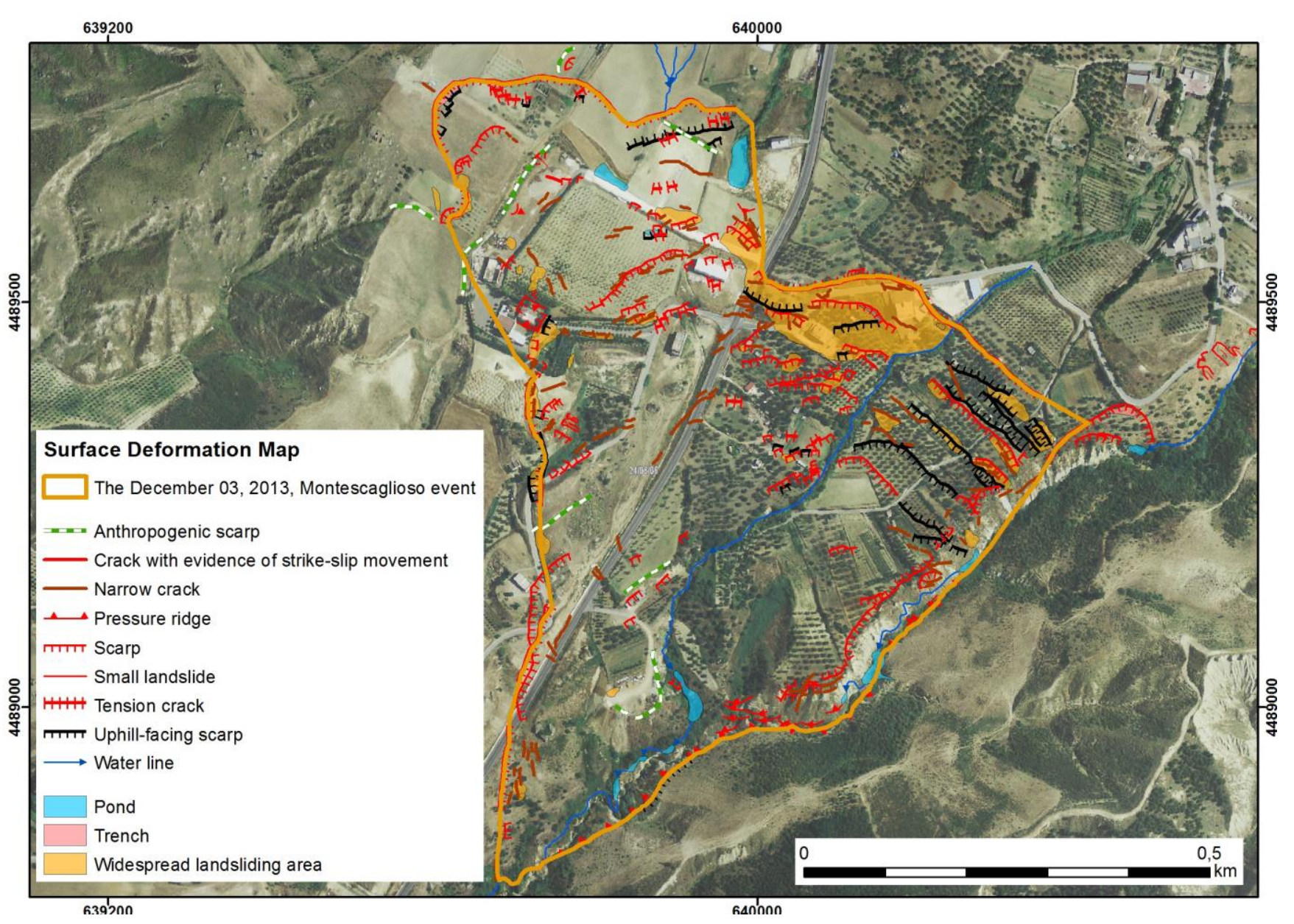


33 S4. Aerial photograph taken form helicopter after the landslide. The location of the Hypermarket, as 34 well as of the most damaged buildings (A and B) is also identified.

35

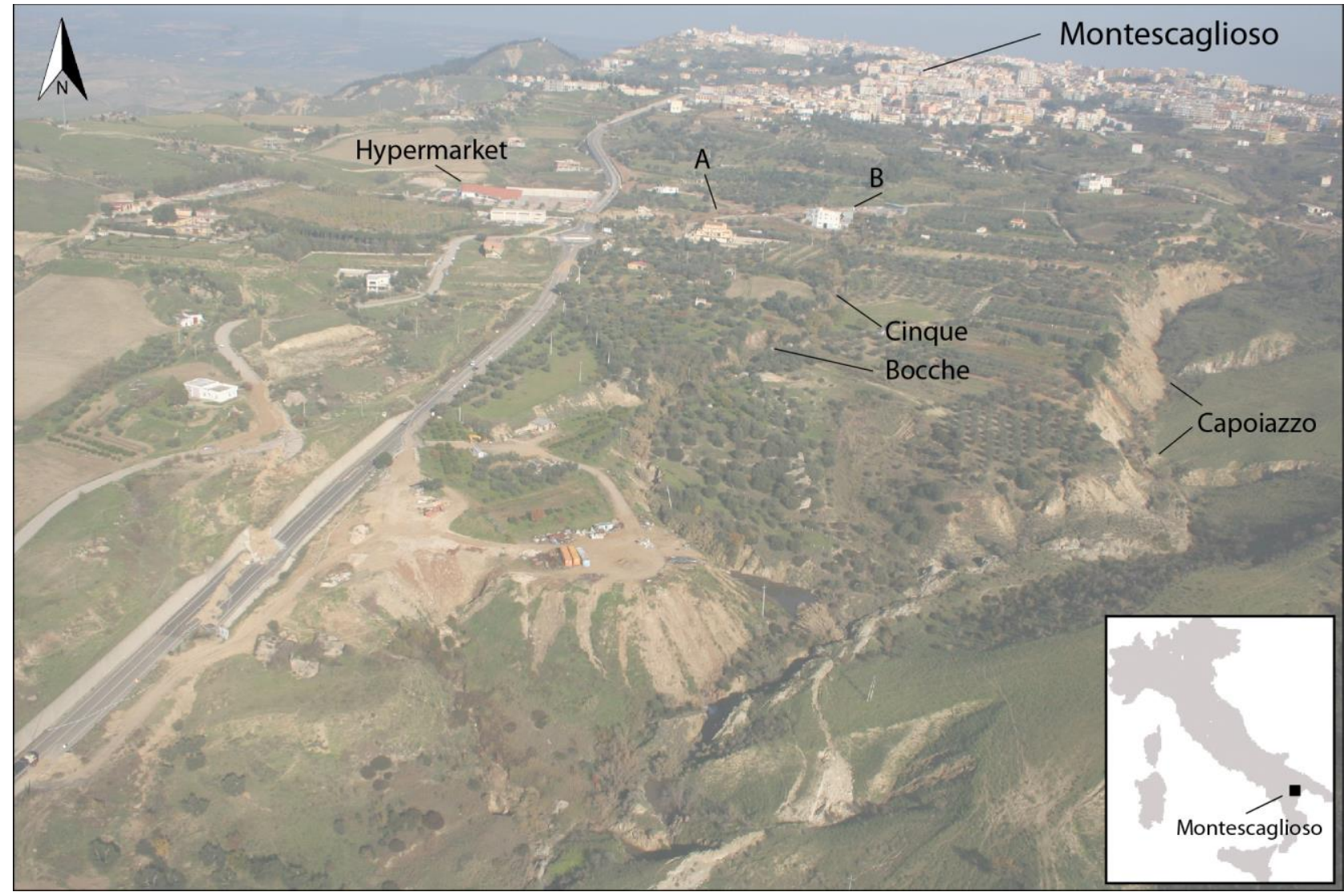


S5. DInSAR interferograms relevant to the Montescaglioso landslide area, achieved by exploiting preand post-event CSK acquisitions over ascending (a-b) and descending (c-d) orbits. (a) 3 December 2013-18 December 2014 interferogram with perpendicular baseline of about $900 \mathrm{~m}$. (b) 16 January 2013-18 December 2014 interferogram, $155 \mathrm{~m}$ of perpendicular baseline. (c) 14 May 2013-12 December 2014 interferogram with perpendicular baseline of $350 \mathrm{~m}$. (d) 10 January 2013-12 December 2014 interferogram, $40 \mathrm{~m}$ of perpendicular baseline. The spatial coherence is not preserved due to the amount of surface displacements, resulting in the complete loss of coherence of the DInSAR signal in the areas experiencing the largest deformations. Note also that the loss of coherence in the area near (but outside) the landslide (highlighted by the dashed white ellipse) is generally due to the large temporal and/or spatial baseline values characterizing the available SAR data pairs across the event.
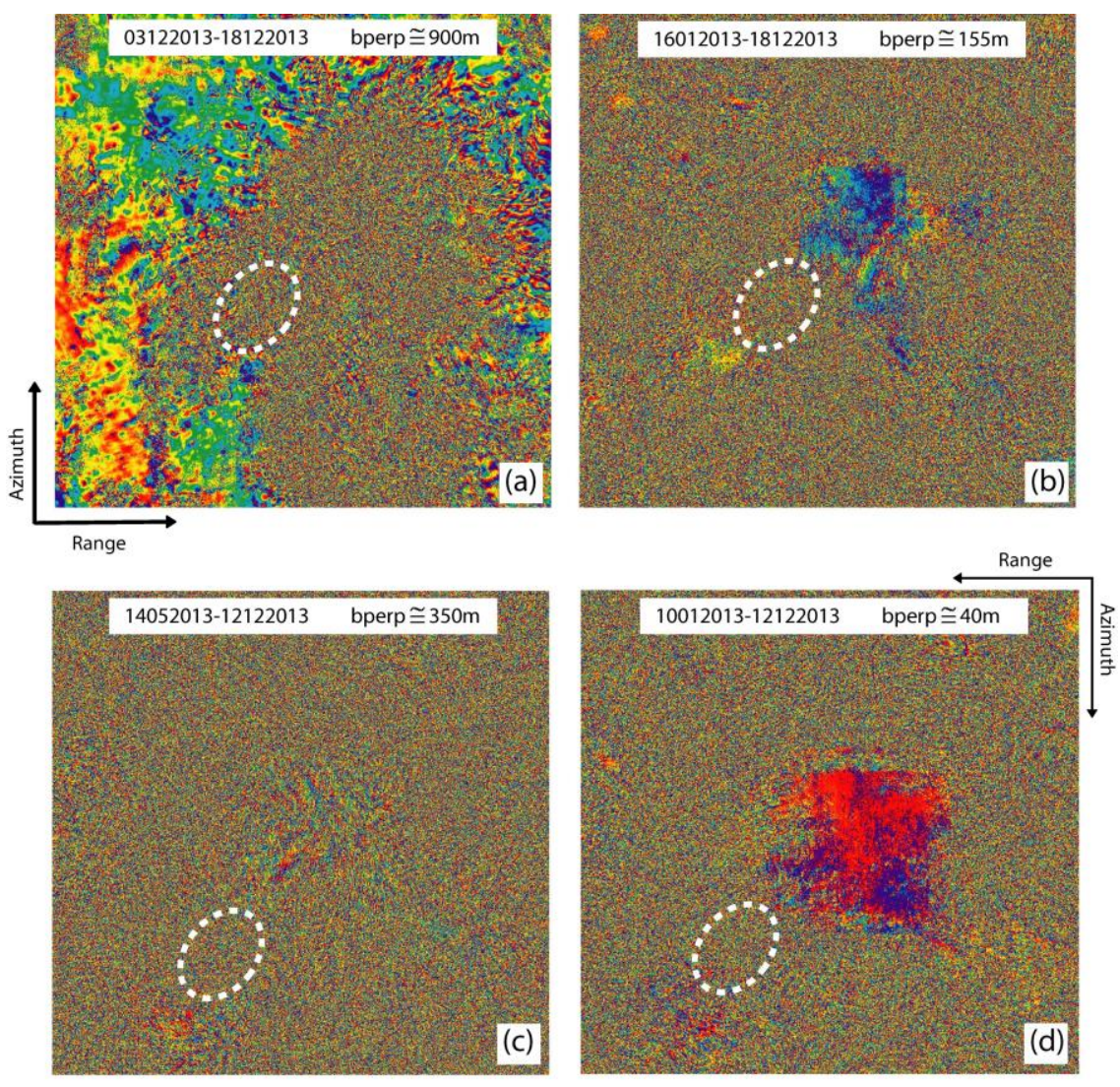
52 S6. SAR data representation in the temporal/perpendicular baseline plane for the (a) ascending and (b) 53 descending CSK datasets. Dates are in the DDMMYYYY format. The black triangles identify the 54 whole CSK acquisitions, while the red ones, connected with the dashed red lines, correspond to the 55 SAR data pairs used for applying the Pixel Offset technique.

56

57
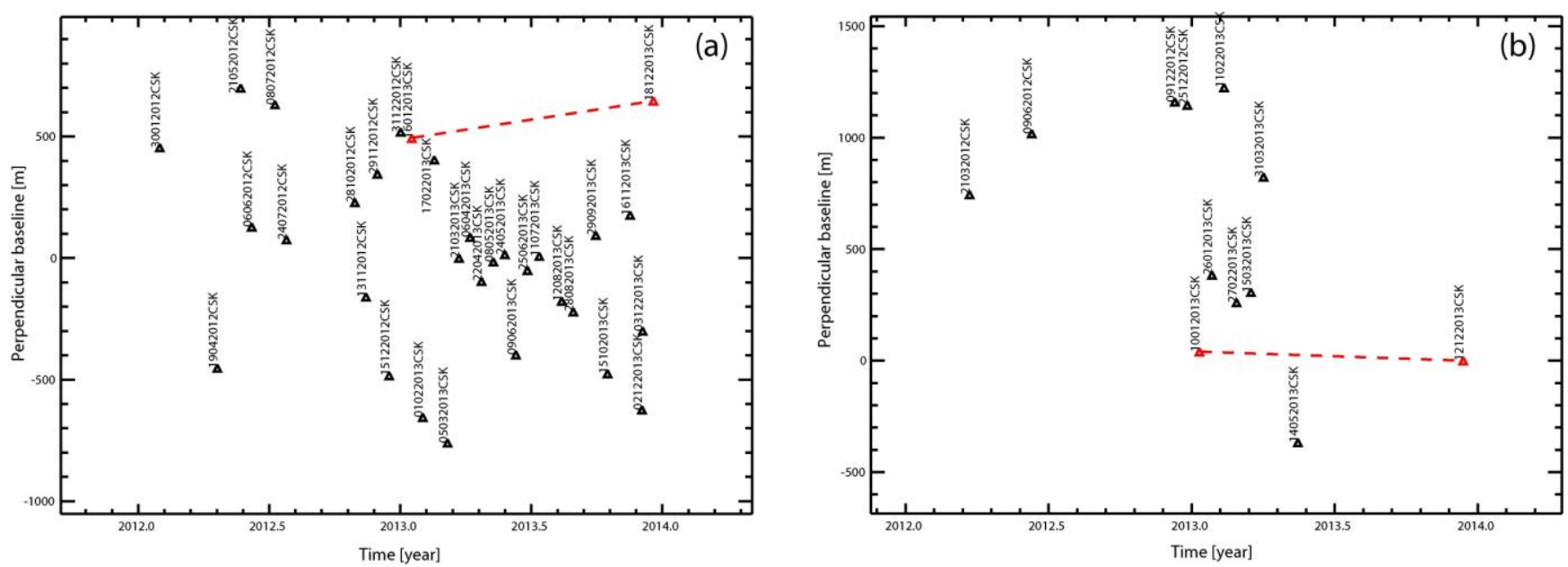